\title{
Mass transfer coefficient for drying of moist particulate in a bubbling fluidized bed
}

\author{
Dr. Yassir T. Makkawi ${ }^{1, *}$ and Prof. Raffaella Ocone ${ }^{2}$
}

1 Chemical Engineering \& Applied Chemistry, Aston University, Birmingham B4 7ET, UK

2 Chemical Engineering, Heriot-Watt University, Edinburgh EH14 4AS, UK

\begin{abstract}
Experiments on drying of moist particles by ambient air were carried out to measure the mass transfer coefficient in a bubbling fluidized bed. Fine glass beads of mean diameter $125 \mu \mathrm{m}$ were used as the bed material. Throughout the drying process, the dynamic material distribution was recorded by Electrical Capacitance Tomography (ECT) and the exit air condition was recorded by a temp/humidity probe. The ECT data were used to obtain qualitative and quantitative information on the bubble characteristics. The exit air moisture content was used to determine the water content in the bed. The measured overall mass transfer coefficient was in the range of $0.0145-0.021 \mathrm{~m} / \mathrm{s}$. A simple model based on the available correlations for bubble-cloud and cloud-dense interchange (two-region model) was used to predict the overall mass transfer coefficient. Comparison between the measured and predicted mass transfer coefficient have shown reasonable agreement with the measurements. The results were also used to determine the relative importance of the two transfer regions.
\end{abstract}

Keywords: Bubbling fluidized bed; Electrical Capacitance Tomography; Mass Transfer Coefficient; Particulate drying

\footnotetext{
* Corresponding author: Tel +44 0)121 204 3398, E-mail: y.makkawi@aston.ac.uk
} 


\section{Introduction}

Bubbling fluidized bed technology is one of the most effective mean for interaction between solid and gas flow, mainly due to its good mixing and high heat and mass transfer rate. When applied to drying of non-porurs wetted solid particles, the water is drawn-off driven by the difference in water concentration between the bubble phase and the surrounding phases. Different mechanisms can regulate this process, depending on the bed hydrodynamics (i.e. bubbles characteristics) and the water content in the bed. Therefore, the design of bubbling fluidized bed dryer requires an understanding of the combined complexity in hydrodynamics and mass transfer mechanism. Mass transfer in fluidized beds is generally known to be more complex than heat transfer. In a gas-solid fluidized bed drier there are different phases which all contribute to the removal of moisture from the wet particles. These are the bubble phase, its surrounding cloud phase and the dense annular phase. Thus, in experimental determination of the overall mass transfer coefficient, one must have in hand detailed quantitative data on the bubble characteristics, as well as the drying rate.

The most widely used mass transfer model of Kunii and Levenspiel [1] expresses the overall mass transfer in a bubbling bed in terms of the cloud-bubble interchange and dense-cloud interchange. The first mechanism is assumed to arise from the contribution of bubble "throughflow" (i.e. circulating gas from the cloud phase and in and out of the bubble) in addition to the diffusion from a thin cloud layer into the bubble. The second mechanism is assumed to arise only from diffusion between the dense phase and the cloud boundary. For particles of about $500 \mu \mathrm{m}$, some researchers assume that the transfer is of a purely diffusional nature, and thus neglect the contribution of bubble throughflow. However, Walker [2] and Sit and Grace [3] pointed out that, pure diffusional model may significantly underestimate, the overall mass transfer coefficient. Kunii and Levenspiel [1] reported that the true overall mass transfer coefficient may fall closer to either of the acting mechanisms depending on the operating conditions (particle size, gas velocity, etc.). They suggested accounting for the first mechanism by summing the diffusional and throughflow, and adding those to the second mechanism in a similar fashion as for additive resistance.

Because of the growing interest on modelling as a tool for effective research and design, researchers on bubbling fluidized bed drying or mass transfer in general are nowadays seeking to validate or develop new mass transfer coefficient equations required for accurate prediction of the process kinetics. Ciesielczyk and Iwanowski [4] presented a fluidized bed drying model based on the interphase mass transfer coefficient. They incorporated Mori and Wen [5] model 
for the bubble diameter into the mass transfer coefficient formulation of Kunii and Levenspiel [1] to predict a generalized drying curve for solid particles in a bubbling bed. The results have shown good agreement with the experimental measurement for group B particles of Geldart classification. Kerkhof [6] discussed some modeling aspect of batch fluidized bed drying, where Kunii and Levenspiel [1] mass transfer coefficient combined with particles internal diffusion model was used to simulate the thermal degradation of life-science products. The study suggested that the exchange between the bubble phase and the particles inside the bubble play an important role in the drying process. Recently, Scala [7] experimentally studied the mass transfer around a freely active particle in a dense fluidized bed of inert particles. He concluded that the active particle only reside in the dense phase and never enters the bubble phase, hence it has no direct contribution to the bubble-dense phase interchanges. This contradicting observation confirms that despite the considerable effort on developing fluidized bed mass transfer coefficients, there still remain uncertainties with respect to the assumptions used in developing these coefficients.

The aim of this study was to measure the overall mass transfer coefficient in a conventional bubbling fluidized bed dryer. The measurement was used for the validation of a simple predictive model based on the available correlations and also to assess the various assumptions used in developing these correlations. For this purpose, the drying rate and the corresponding mass balance were calculated from the measurement of the drying air at outlet conditions. Information on the bed hydrodynamics were obtained from Electrical Capacitance Tomography (ECT) images.

\section{Experimental}

The primary objective of the experiment was to measure the mass transfer coefficient for a drying process in a conventional bubbling fluidized bed. This required detailed knowledge of the fluidized bed hydrodynamics and drying rate. For this purpose, non-porous wet solid particles of glass beads were contained in a vertical column and fluidized using air at ambient temperature. The fluidising air was virtually dry and obtained from a high-pressure compressor. An advanced imaging ECT sensor was used to provide dynamic information on the fluidized bed material distribution. The sensor was connected to a data acquisition unit and a computer. The air outlet temperature and its relative humidity were recorded using a temperature/humidity probe. Since the air condition at the inlet of the fluidization column was constant and completely independent 
of the bubbling bed operating conditions, only one probe was installed at the freeboard (air exit). The detailed experimental set-up is shown in Figure 1.

\subsection{Equipment and materials}

The fluidization was carried out in a cast acrylic column, $13.8 \mathrm{~cm}$ diameter and $150 \mathrm{~cm}$ high. The column was transparent, thus allowing for direct visual observation. A PVC perforated gas distributor with a total of 150 holes ( $1.8 \%$ free area), was placed $24 \mathrm{~cm}$ above the column base. The upstream piping was fitted with pressure regulator, moisture trap, valve and three parallel rotamaters. A one-step valve was connected before the moisture trap and was used as the upstream main flow controller. The particles used were ballotini (non-porous glass beads) with a mean diameter of $125 \mu \mathrm{m}$ and a density of $2500 \mathrm{~kg} / \mathrm{m}^{3}$ (Geldart A/B mixture). The detailed physical properties of the particles are given in Tab. 1. Distilled water at ambient condition was used to wet the particles. A variable speed granule shaker was utilised to produce the final wetted mixture.

The Electrical Capacitance Tomography imaging system used (ECT from Process Tomography Limited, Manchester, UK), consisted of two adjacent sensor rings each containing 8 electrode of $3.8 \mathrm{~cm}$ length. All electrodes were connected to the computer through a data acquisition module (DAM 2000). The PC was equipped with custom communication hardware and software (ECT32) that allow for online and off-line dynamic image display. The system is capable of taking crosssectional images of the bed at two adjacent levels simultaneously at 100 frames per second. Further details about the ECT system used in this study and its application to fluidization analysis can be found in Makkawi et al. [8] and Makkawi and Ocone [9].

The exit air quality was measured using a temperature and humidity probe (Type: Vaisala HMI 31, Vantaa, Finland, measuring range: $0-100 \% \mathrm{RH},-40-115 \mathrm{C}^{\circ}$ ). The probe was hung by a connecting wire inside the fluidized bed freeboard approximately $10 \mathrm{~cm}$ above the maximum expanded bed height.

\subsection{Procedure}

The experimental procedure employed was completely non-intrusive. This is described in the following steps in the order of their occurrence:

(a) A total weight of $4.5 \mathrm{~kg}$ of a dry ballotini mixture was placed in a granule shaker after being wetted by distilled water. The shaker was firmly clamped and operated 
continuously for at least 25 minutes to ensure an even distribution of water content. Distilled water was used to eliminate any possible interference with the ECT signal (ECT works for non-conducting materials only)

(b) The wetted particles were then loaded into the fluidization column. Prior to commencement of drying, the ECT sensor was calibrated for two extreme cases. This was carried out by sliding the ECT sensor up to the freeboard to calibrate for the empty bed case, and down to the static bed area to calibrate for the packed bed case. It should be mentioned that, because the water content was limited to a maximum of $45 \mathrm{ml}(1 \%$ moisture on dry solid weight basis), the possible changes in the particle/air permittivity during the drying process would be negligible. Further details on the sensitivity of the ECT system to moisture content in the fluidized bed dryer can be found in Chaplin and Pugsley [10] and Chaplin et al. [11].

(c) The wet bed material was fluidized at the required air flow rate. This was carefully adjusted to ensure the bed operation at the single bubble regime. The temperature and relative humidity were recorded at 2 minutes intervals. Simultaneously, and at the 5 minutes intervals, a segment of 60 seconds ECT data were recorded. At the same time, the expanded bed height during fluidization was obtained from visual observations.

(d) Finally, the drying rate was obtained from the measured air flow rate and temperature/humidity data at inlet and outlet using psychometric charts and mass balance calculations. The recorded ECT data were further processed off-line and loaded into in-house developed MATLAB algorithm to estimate the bubble characteristics.

The above described procedure was repeated for the three different operating conditions summarized in Tab. 2. To ensure data reproducibility, each operating condition was repeated three times, making a total of nine experiment tests.

\subsection{Measurement of mass transfer coefficient}

Considering a section of the bed as shown in Figure 2, the overall mass transfer coefficient between the bubble phase and the surrounding dense phase, $k_{d b}$, can be defined by the following rate equation:

$$
-u_{b} \frac{d C_{b}}{d z}=\left(\frac{S_{b}}{V_{b}}\right) k_{d b}\left(C_{d}-C_{b}\right)
$$


where $C_{b}$ is the water concentration in the bubble phase, $C_{d}$ is the concentration in the surrounding dense phase, $u_{b}, S_{b}$ and $V_{b}$ are characteristic features of the bubble representing the rising velocity, the interphase area and the volume, respectively. For moisture-free inlet air, Eq. 1 is subject to the following boundary conditions:

$C_{b}=\left(C_{\text {in }}\right)_{\text {air }}=0$ at $z=0$ and $C_{b}=\left(C_{\text {out }}\right)_{b}$ at $z=H$

The bubble moisture content at the outlet $\left(C_{\text {out }}\right)_{b}$ can be given by:

$\left(C_{\text {out }}\right)_{b}=\frac{\text { (drying rate) }}{\text { (bubble mass flow rate) }}=\frac{m_{\text {air }}\left(C_{\text {out }}-C_{\text {in }}\right)_{\text {air }}}{m_{b}}$

where $m_{\text {air }}$ and $m_{b}$ are the mass flow rate of the fluidising air and bubbles respectively. Because of the assumption that the bubbles rise much faster than the gas through the dense phase and the inlet air was virtually dry, Eq. 3 reduces to:

$\left(C_{\text {out }}\right)_{b}=\left(C_{\text {out }}\right)_{\text {air }}$

where $\left(C_{\text {out }}\right)_{\text {air }}$ is obtained from the measured temperature and humidity at the bubbling bed surface.

For a spherical bubble, $S_{b} / V_{b}$ ratio appearing in Eq. 1 reduces to $6 / d_{b}$, where $d_{b}$ is the bubble diameter. It should be mentioned that for a perforated distributor (such as the one used in this experiment), coalescence of bubbles mainly takes place at a few centimetres above the distributor, therefore, the entrance effects are neglected and the bubble characteristics are assumed to be independent of height (this was confirmed from the ECT images).

Finally, assuming that the water concentration in the dense phase is uniform and remains unchanged during the bubble rise $\left(C_{d}=w_{\text {water }} / w_{\text {bed }}\right)$ and integrating Eq. 1 from $z=0$ to $z=H$, the mass transfer coefficient is obtained as follows:

$k_{d b}=-\left(\frac{d_{b} u_{b}}{6 H}\right) \ln \left[\frac{C_{d}-\left(C_{\text {out }}\right)_{b}}{C_{d}}\right]$

where $d_{b}, u_{b}$ and $H$ are the bubble diameter, the bubble velocity and the expanded bed height, respectively. 


\subsection{Measurement of bubble characteristics}

Experimental determination of the overall mass transfer requires knowledge of the bubble diameter and velocity (see Eq. 5). Using the ECT, the size and velocity of the bubbles (or 'voids') in a gas-solid fluidized bed can be obtained. The distinct lowering of the solid fraction when the bubble passes across the sensor area allows for identification of the bubble events in a given time and space. The bubble velocity was then calculated from the delay time determined from a detailed analysis of the signal produced by the two adjacent sensors, such that:

$u_{b}=\frac{\delta}{\Delta t_{b}}$

where $\Delta t_{b}=t_{b 2}-t_{b 1}, t_{b 1}$ and $t_{b 2}$ represent the time when the bubble peak passes through the lower and upper level sensors respectively, and $\delta$ represents the distance between the centre of the two sensors, which is $3.8 \mathrm{~cm}$. The method is demonstrated for a typical ECT data in Figure 3.

The bubble diameter was obtained from the ECT data of relative solid fraction at the moment of bubble peak across the sensor cross-section. From this, the bed voidage fraction (the fraction occupied by bubbles) was calculated as follows:

$d_{b}=D \gamma$

where $\gamma=(1-P)$ is the bubble fraction, $P$ is the relative solid fraction (i.e. packed bed: $P=1$; empty bed: $P=0)$ and $D$ is the bed/column diameter. This procedure is demonstrated for a typical ECT data in Figure 4.

Further details on the application of twin-plane ECT for the measurements of bubble characteristics in fluidized bed can be found in Makkawi and Wright [12].

\section{Theoretical Models}

\subsection{Estimation of mass transfer coefficient}

In a bubbling fluidized bed, it is widely believed that mass transfer occurs in two distinct regions: at the dense-cloud interface, $k_{d c}$, and at the cloud-bubble interface, $k_{c b}$. The overall mass transfer may be dense-cloud controlled; cloud-bubble controlled or equally controlled by the two mechanisms depending on the operating conditions. The following theoretical formulations of these acting mechanisms are mainly based on the following assumptions:

i. The fluidized bed operates at single bubble regime. 
ii. The bubbles are spherically shaped.

iii. The bubble rise velocity is fast $\left(u_{b}>5 U_{m f} / \varepsilon_{m f}\right)$.

iv. The contribution of particles presence within the bubble is negligible.

v. The contribution of the gas flow through the dense phase is assumed to be negligible.

As evident from the tomographic analysis of the bubble characteristics, assumptions (i)-(iv) are to a great extent a good representation of the actual bubbling behaviour.

\section{Cloud-bubble interchange:}

According to Davidson and Harrison [13], the mass transfer at the bubble-cloud interface arises from two different contributions:

1. Diffusion across a limited thin layer where the mass transfer coefficient is estimated by:

$$
k_{c b}=0.975 D^{0.5}\left(\frac{g}{d_{b}}\right)^{0.25}
$$

2. Convection contribution as a result of bubble throughflow, which consists of circulating gas between the bubble and the cloud (leaving the bubbles from top and re-entering it from the base as shown in Figure 5. Based on the analysis of Davidson and Harrison [13], Murray [14] reported the following corrected equation for the contribution of bubble throughflow:

$$
k_{q}=0.25 U_{m f}
$$

Kunii and Levenspiel [1] recommended adding both acting mechanisms, thus the mass transfer coefficient between the bubble-cloud is given by:

$$
k_{c b}=0.975 D^{0.5}\left(\frac{g}{d_{b}}\right)^{0.25}+0.25 U_{m f}
$$

\section{Dense-cloud interchange:}

Utilizing the Higbie penetration model [15], the mass transfer coefficient at the dense-cloud interface is expressed in terms of the bubble-cloude exposure time and the effective diffusivity as follows [16]:

$k_{d c}=\left(\frac{4 D_{e} \varepsilon_{m f}}{\pi t}\right)^{0.5}$ 
where $t=\frac{d_{c}}{u_{b}}$ is the exposure time between the bubble and the cloud.

From the analysis of tomographic images of the bubbles and its boundaries, it is observed that the cloud diameter (the outer ring in Figure 5 ) is in the range of 1.2-1.8 bubble diameters, and that the concentration of the particles within the core of the rising bubble is virtually negligible. Therefore, in the current analysis we assumed that $d_{c} \sim 1.5 d_{b}$ and that the contribution of the particles circulation between the bubble and the surrounding phases to the overall mass transfer process is negligible. The effective diffusivity, $\mathscr{D}_{e}$ is assumed equal to the molecular diffusivity, $\mathscr{D}$. With these approximations, Eq. 11 reduces to:

$k_{d c}=0.92\left(\frac{\mathscr{D} \varepsilon_{m f} u_{b}}{d_{b}}\right)^{0.5}$

\section{Overall bed exchange:}

For an equally significant contribution from cloud-bubble and dense-cloud interchanges, Kunii and Levenspiel [1] suggested adding both contributions in a analogy to parallel resistances, such that the overall bed mass transfer coefficient $\left(k_{d b}\right)$ is given by:

$\frac{1}{k_{d b}}=\frac{1}{k_{d c}}+\frac{1}{k_{c b}}$

Substituting Eq. 10 and 12 into Eq. 13 yields the overall mass transfer coefficient as follows:

$k_{d b}=\frac{A_{1} B_{1}}{d_{b}^{0.5}\left(A_{1}+B_{1}\right)}$

where

$$
\begin{aligned}
& A_{1}=0.975 \mathscr{D}^{0.5}\left(d_{b} g\right)^{0.25}+0.25 U_{m f} d_{b}^{0.5} \\
& B_{1}=0.92\left(\mathscr{D} \varepsilon_{m f} u_{b}\right)^{0.5}
\end{aligned}
$$

\section{Results and discussions}

\subsection{Hydrodynamics}

Figure 6 shows the measured bubble velocity and bubble diameter as a function of the water content in the bed. These measurements were taken at different time intervals during the drying process. Each data point represents the average over 60 seconds. Both parameters vary slightly 
within a limited range. These hydrodynamic observations suggest that the bubble characteristics almost remain independent of the water content, at least within the range of operation conditions considered here. This is due to the fact that the initial water content in the bed was not significant enough to cause considerable hydrodynamic changes.

Among the many available correlations, the following equations have been found to provide good matches with the experimental measurements:

\section{Bubble velocity [1]:}

$u_{b}=\psi\left(U-U_{m f}\right)+\alpha\left[0.711\left(g d_{b}\right)^{0.5}\right]$

This a modified form of Davidson and Harrison [13] equation, where $\psi=0.75$ and $\alpha=3.2 D_{c}^{1 / 3}$ are correction factors suggested by Werther [17] and Hilligardt and Werther [18].

\section{Bubble diameter [5]:}

$d_{b}=0.652\left[D_{o}-\exp \left(-0.3 z / D_{c}\right)\right]+\frac{0.347 D_{o}}{n_{o}^{0.4}} \exp \left(-0.3 z / D_{c}\right)$

where

$D_{o}=\left[\frac{\pi}{4 D_{c}^{2}}\left(U-U_{m f}\right)\right]^{0.4}$

$U_{m f}$ used in Eqs 17 and 19 was given by:

$U_{m f}=\frac{d_{p}^{2}\left(\rho_{p}-\rho_{g}\right) g}{150 \mu} \frac{\varepsilon_{m f}^{3} \phi_{p}}{\left(1-\varepsilon_{m f}\right)}$

For the operating condition given in Tab. 2, Eq. 20 gives $U_{m f}=0.065 \mathrm{~m} / \mathrm{s}$, which closely matches the measured value of $0.062 \mathrm{~m} / \mathrm{s}$. Despite the fact that Eqs. $17-20$ were all originally developed for dry bed operations; they seem to provide a reasonable match with the experimental measurements made here under wet bed condition (Figure 6). This is not surprising, since the water content in the bed was relatively low as discussed above. The expanded bed height, used in the experimental estimation of the overall mass transfer coefficient (Eq. 4), is shown in Figure 7. A clear gradual (but limited) increase in the bed expansion as the water is removed from the bed can be noticed. 


\subsection{Drying rate}

The drying rate curves for the three experiments conducted are shown in Figure 8 . The curve fitting is used to obtain the water content in the bed at various times. From Figure 8 , it may be concluded that the time of drying is directly proportional to the initial water content, and inversely proportional to the drying air flow rate. For instance, at an air velocity of $0.47 \mathrm{~m} / \mathrm{s}$, this time was reduced by half when reducing the initial water content from $C_{o, b e d}=10 \%$ to $C_{o, b e d}=5 \%$, while at the initial water content of $C_{o, b e d}=10$, this time was $\sim 35 \%$ longer when reducing the air velocity from $0.47 \mathrm{~m} / \mathrm{s}$ to $0.33 \mathrm{~m} / \mathrm{s}$.

The water concentration in the bed as a function of the drying time is shown in Figure 9. This was obtained from the integration of the drying curve function, $F(t)$, and subtracting it from the initial water content, $w_{o}$, such that:

$$
w_{t}=w_{o}-\int_{0}^{t} F(t) d t
$$

\subsection{Mass transfer coefficient}

\subsubsection{Experimental measurement}

The measured overall mass transfer coefficient, $k_{d b}$, as a function of the water concentration in the bed is shown in Figure 10. The values of $k_{d b}$ falls within the range of $0.0145-0.021 \mathrm{~m} / \mathrm{s}$. It is interesting to note that this range is close to the value one can obtain from the literature for the mass transfer coefficient from a free water surface to an adjacent slow moving ambient air stream $(\sim 0.015 \mathrm{~m} / \mathrm{s})[19]$.

\subsubsection{Comparison with other experimental data}

Walker [2] and Sit and Grace [3] measured the mass transfer coefficient in a two-dimensional fluidized bed. The technique employed involves the injection of ozone-rich bubble into an airsolid fluidized bed. Their experimental data for various particle sizes are compared with our measurement in Figure 11. Taking into consideration the differences in the experimental set-up and operating conditions, the agreement with our measurement appears satisfactory for the particle size considered in this study. 


\subsubsection{Comparison with theoretical prediction}

Figure 12 compares the measured mass transfer coefficient with the theoretical predictions obtained from the formulations given in section 3.1. The boundaries for the overall mass transfer coefficient are given by: (i) a model accounting for cloud-bubble contribution, dense-bubble contribution as well as the bubble through flow contribution, giving the lower limit (Eq. 14) and (ii) a model accounting for the cloud-bubble contribution only, giving the upper limit (Eq. 10). The results also suggest that, within the operating conditions considered here, the drying may well be represented by a purely diffusional model, controlled by either the resistance residing at the dens-cloud interface, or the cloud-bubble interface.

Finally, Tab. 3 shows the numerical values of the various mass transfer contributions obtained from Eqs 8-16. It is shown that the estimated diffusional resistances, as well as the contribution from the bubble throughflow, are all of the same order of magnitude. Previously, Geldart [20] argued that the bubble throughflow is not important for small particles and may be neglected. According to our analysis, this may well be the case here. However, generalization of this conclusion should be treated with caution especially when dealing with larger particles.

\section{Conclusion}

Mass transfer coefficient in a bubbling fluidized bed dryer has been experimentally determined. This work is the first to utilise an ECT system for this purpose. The ECT allowed for quantification of the bubble diameter and velocity, as well as providing new insight into the bubble-cloud-dense boundaries.

The measured overall mass transfer coefficient was in the range of $0.045-0.021 \mathrm{~m}^{2} / \mathrm{s}$. A simple hydrodynamic and mass transfer model, based on the available correlations was used to predict the mass transfer coefficient in a bubbling fluidized bed. Despite the complexity of the process, and the number of assumption employed in this analysis, the model based on pure diffusional mass transfer seems to provide satisfactory agreement with the experimental measurements.

This work set the seen for future experimental investigations to obtain a generalised correlation for the mass transfer coefficient in fluidized bed dryer, particularly that utilizes the ECT or other similar imaging techniques. Such a correlation is of vital importance for improved fluidized bed dryer design and operation in its widest application. A comprehensive experimental program, covering a wider range of operating conditions (particle size, gas velocity, water content, porous/non-porous particles) is recommended. 


\section{Nomenclature}

$\begin{array}{lll}A & {\left[\mathrm{~m}^{2}\right]} & \text { column/bed cross-sectional area } \\ A_{1}, B_{1} & {\left[\mathrm{~m}^{1.5} \mathrm{~s}^{-1}\right]} & \text { parameters defined in Eqs. 15, 16 respectively } \\ C_{d}, C_{b} & {[-]} & \text { water concentration in the dense and bubble phases respectively, } \mathrm{kg} / \mathrm{kg} \\ d, D & {[\mathrm{~m}]} & \text { diameter } \\ \mathcal{D}, \mathscr{D}_{e} & {\left[\mathrm{~m}^{2} \mathrm{~s}^{-1}\right]} & \text { molecular and effective diffusivity respectively } \\ g & {\left[\mathrm{~ms}^{-2}\right]} & \text { gravity acceleration constant } \\ H & {[\mathrm{~m}]} & \text { expanded bed height } \\ k_{d b} & {\left[\mathrm{~ms}^{-1}\right]} & \text { overall mass transfer coefficient (between dense and bubble phases) } \\ k_{c b} & {\left[\mathrm{~ms}^{-1}\right]} & \text { mass transfer coefficient between cloud and bubble phases } \\ k_{d c} & {\left[\mathrm{~ms}^{-1}\right]} & \text { mass transfer coefficient between dense and cloud phases } \\ m & {\left[\mathrm{kgs}^{-1}\right]} & \text { mass flow rate } \\ P & {[-]} & \text { relative solid fraction } \\ S & {\left[\mathrm{~m}^{2}\right]} & \text { surface area } \\ U & {\left[\mathrm{~ms}^{-1}\right]} & \text { superficial gas velocity } \\ u & {\left[\mathrm{~ms}^{-1}\right]} & \text { velocity } \\ V & {\left[\left(\mathrm{~m}^{3}\right)\right.} & \text { volume } \\ w & {[\mathrm{~g}]} & \text { bed water content } \\ Z & {\left[\mathrm{~m}^{3}\right.} & \text { axial coordinate }\end{array}$

\section{Greek symbols}

$\begin{array}{lll}\varepsilon & {[-]} & \text { bed voidage } \\ \gamma & {[-]} & \text { bubble fraction } \\ \rho & {\left[\mathrm{kg} \cdot \mathrm{m}^{-3}\right]} & \text { density } \\ \delta & {[\mathrm{m}]} & \text { distance between the centre of the two ECT sensors } \\ \phi_{p} & {[-]} & \text { particle sphericity }\end{array}$

\section{Subscripts}

$\begin{array}{ll}b & \text { bubble } \\ c & \text { cloud } \\ d & \text { dense } \\ m f & \text { minimum fluidization }\end{array}$




\section{References}

[1] D. Kunii, and O. Levenspiel, Fluidization Engineering. Second edition, ButterworthHeinemann, Boston 1991.

[2] B. V. Walker, Transaction Institute of Chemical Engineers 1975, 53, 225.

[3] S.P. Sit, and J. R. Grace, Chemical Engineering Science 1978, 33, 1115.

[4] W. Ciesielczyk and J. Iwanowski, Powder Technology 2006, 24, 1153.

[5] S. Mori and C. Y. Wen, AICHE J. 1975, 21, 109.

[6] P. J. A. M. Kerkhof, Chemical Engineering and Processing 2000, 39, 69.

[7] F. Scala, Chemical Engineering Science 2007, 62, 4159.

[8] Y. Makkawi, P. Wright, R. Ocone, Powder Technology 2006, 163, 69.

[9] Y. Makkawi and R. Ocone, Chemical Engineering Science 2007, 62, 4304.

[10] G. Chaplin and T. Pugsley, Chemical Engineering Science 2005, 60, 7022.

[11] G. Chaplin, T. pugsley, L. van der Lee, A. Kantzas, C. Winters, Measurement Science and Technology 2005, 16, 281.

[12] Y. Makkawi and P. C. Wright, Powder Technology 2004, 148, 142.

[13] J. Davidson and D. Harrison, Fluidized Particles, Cambridge University Press, Cambridge 1963.

[14] J. D. Murray, Journal of Fluid Mechanics 1965, 22, 57.

[15] R. Higbie, in Fluidization Engineering, Second edition (Eds: D. Kunii and O. Levenspiel), Butterworth-Heinemann, Boston, 1991. 256.

[16] T. Chiba, and H. Kobayashi, Chemical Engineering Science 1970, 25,1375.

[17] J. Werther, in Fluidization Engineering, Second edition (Eds: D. Kunii and O. Levenspiel), Butterworth-Heinemann, Boston, 1991. 147

[18] K. Hilligardt and J. Werther, German Chemical Engineering 1986, 9, 215.

[19] G. Saravacos and Z. Maroulis, Transport properties of foods, CRC Press, 2001.

[20] D. Geldart, Gas Fluidization Technology, John Wiley and Sons, Chichester, UK, 1986. 
Table 1

\begin{tabular}{|c|c|}
\hline Geldart Group & $\mathrm{A} / \mathrm{B}$ \\
\hline Particle size range $(\mu \mathrm{m})$ & $50-180$ \\
\hline Mean particle diameter $(\mu \mathrm{m})$ & 125 \\
\hline Particle density $\left(\mathrm{kg} / \mathrm{m}^{3}\right)$ & 2500 \\
\hline Bulk density $\left(\mathrm{kg} / \mathrm{m}^{3}\right)$ & 1300 \\
\hline Hardness according to Mohs & $\geq 6 \%$ \\
\hline Sphericity & $\geq 80 \%$ \\
\hline Pores & $<0.02 \mathrm{~nm}$ \\
\hline Material & Pure soda lime glass ballotini. \\
\hline Chemical composition & $\begin{array}{l}\mathrm{SiO}_{2}=72 \%, \mathrm{Na}_{2} \mathrm{O}=13 \%, \mathrm{CaO}=9 \%, \mathrm{MgO}=4 \%, \mathrm{Al}_{2} \mathrm{O}_{3}=1 \%, \mathrm{~K}_{2} \mathrm{O} \\
\& \mathrm{Fe}_{2} \mathrm{O}_{3}=1 \%\end{array}$ \\
\hline Commercial name & Glass beads - type S, Art. 4500 \\
\hline Electric permittivity & $\sim 3.1$ \\
\hline
\end{tabular}


Table 2

\begin{tabular}{|c|c|c|c|}
\hline Experimental unit & \multicolumn{3}{|c|}{ Operating conditions } \\
\hline Column & \multicolumn{3}{|c|}{ Diameter $=13.8 \mathrm{~cm}$, height $=150 \mathrm{~cm}$, material: cast acrylic } \\
\hline Distributor & \multicolumn{3}{|c|}{ Perforated PVC; 150 holes of $2 \mathrm{~mm}$ dia. } \\
\hline Particles & \multicolumn{3}{|c|}{$d_{p}=125 \mu \mathrm{m}, \rho_{p}=2500 \mathrm{~kg} / \mathrm{m}^{3}$, Material: glass } \\
\hline Fluidization fluid & \multicolumn{3}{|c|}{ Air at ambient condition $\left(20^{\circ} \mathrm{C}\right)$} \\
\hline \multirow[t]{2}{*}{ Static bed height } & $20 \mathrm{~cm}$ & & \\
\hline & Exp. 1 & Exp. 2 & Exp. 3 \\
\hline Fluidization velocity (m/s) & 0.34 & 0.47 & 0.47 \\
\hline Initial water content (wt\%) & 1.0 & 1.0 & 0.5 \\
\hline
\end{tabular}


Table 3

\begin{tabular}{cccc|ccc}
\hline \multicolumn{4}{c}{ Experimental } & \multicolumn{3}{c}{ Theoretical } \\
\hline $\begin{array}{c}\text { Gas } \\
\text { velocity }\end{array}$ & $\begin{array}{c}\text { bubble } \\
\text { characteristics }\end{array}$ & $\begin{array}{c}\text { Overall mass } \\
\text { transfer coeff. }\end{array}$ & $\begin{array}{c}\text { Dense-cloud } \\
\text { interchange } \\
\text { (diffusion only) }\end{array}$ & $\begin{array}{c}\text { Cloud-bubble } \\
\text { interchange } \\
\text { (diffusion only) }\end{array}$ & $\begin{array}{c}\text { Bubble } \\
\text { throughflow }\end{array}$ \\
\hline$U(\mathrm{~m} / \mathrm{s})$ & $d_{b}(\mathrm{~m})$ & $u_{b}(\mathrm{~m} / \mathrm{s})$ & $k_{d b}(\mathrm{~m} / \mathrm{s})$ & $k_{d c}(\mathrm{~m} / \mathrm{s})$ - Eq. 12 & $k_{c b}(\mathrm{~m} / \mathrm{s})$ - Eq. 8 & $k_{q}(\mathrm{~m} / \mathrm{s})$ - Eq. 9 \\
\hline 0.35 & 0.04 & 0.99 & 0.0145 & 0.0178 & 0.0194 & 0.015 \\
\hline
\end{tabular}




\section{List of Figs}

Figure 1. Experimental set up (a) Schematic of the fluidized bed (b) A photograph of the installation

Figure 2. Schematic representation of the method used in experimental calculation of the overall mass transfer coefficient

Figure 3. Estimation of bubble velocity from ECT data

Figure 4. Estimation of bubble diameter from ECT measurement (a) bubble diameter (b) ECT solid fraction (b) ECT slice images

Figure 5. Mass transfer mechanism between dense-cloud and cloud-bubble phases demonstrated in a typical ECT image of an isolated rising clouded bubble in a fluidized bed

Figure 6. Variation of the bubble velocity and bubble diameter during the drying process

Figure 7. Variation of expanded fluidized bed height during the drying process

Figure 8. Drying rate curves for the three conducted experiments

Figure 9. Variation of water content during drying

Figure 10. Experimentally measured overall mass transfer coefficient

Figure 11. Experimental overall mass transfer coefficient in comparison with other previously reported results

Figure 12. Comparison between experimental measurement and various theoretical models for mass transfer coefficients

\section{List of Tables}

Table 1. Physical and chemical properties of the dry particles

Table 2. Summary of experimental operating conditions

Table 3. The measured overall mass transfer coefficient for one selected operating condition in comparison to the theoretical predictions of various contributions. 


\section{Summary}

The drying of moist particles in a bubbling fluidized bed mainly takes place as a result of mass transfer between the bubbles and the surrounding dense solid phase. In this study, the mass transfer coefficient was estimated from experimental measurement of the bubble characteristics and drying air condition. The results were used for the validation of empirical correlations and for assessing the various assumptions used in developing these correlations. 


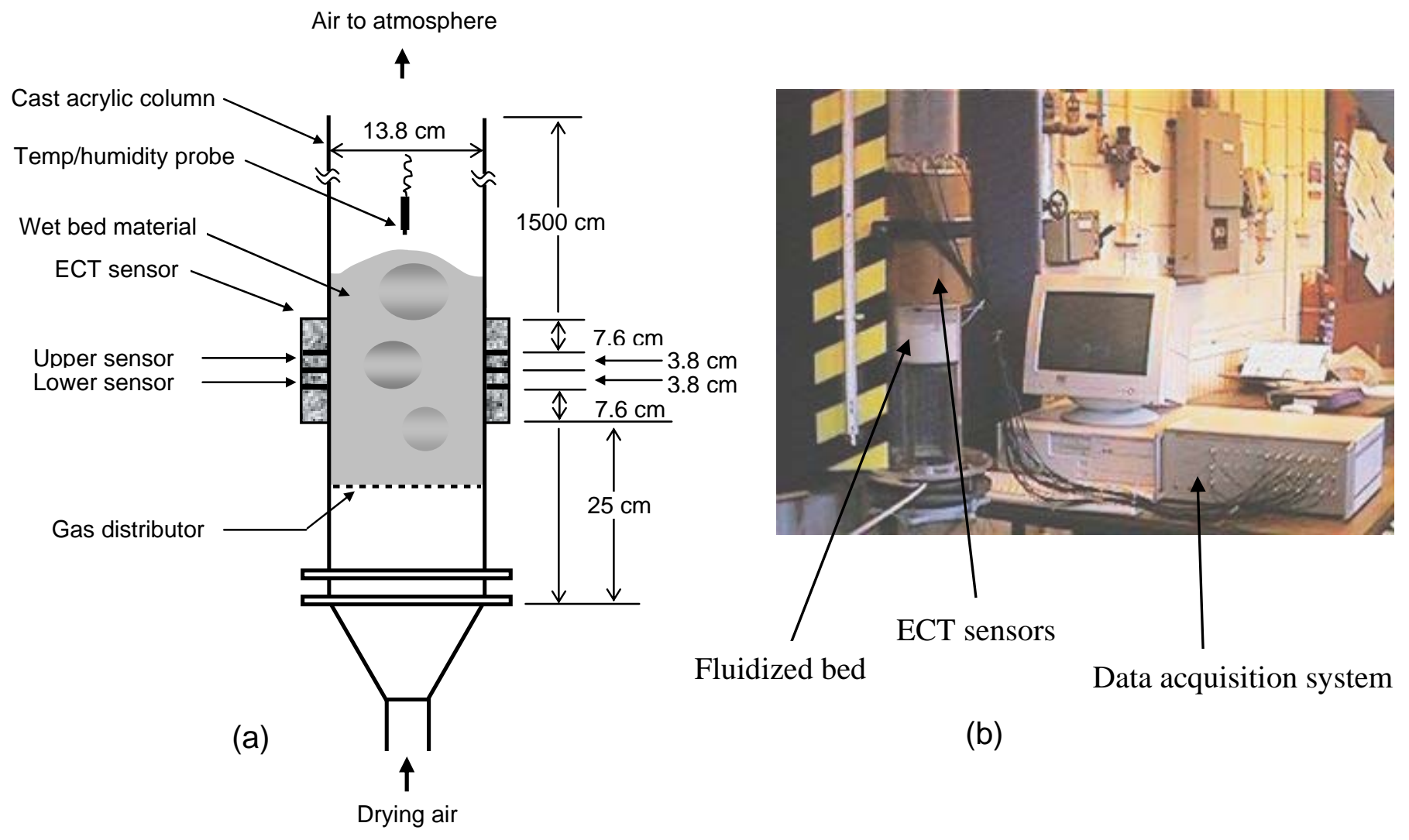

Figure 1 


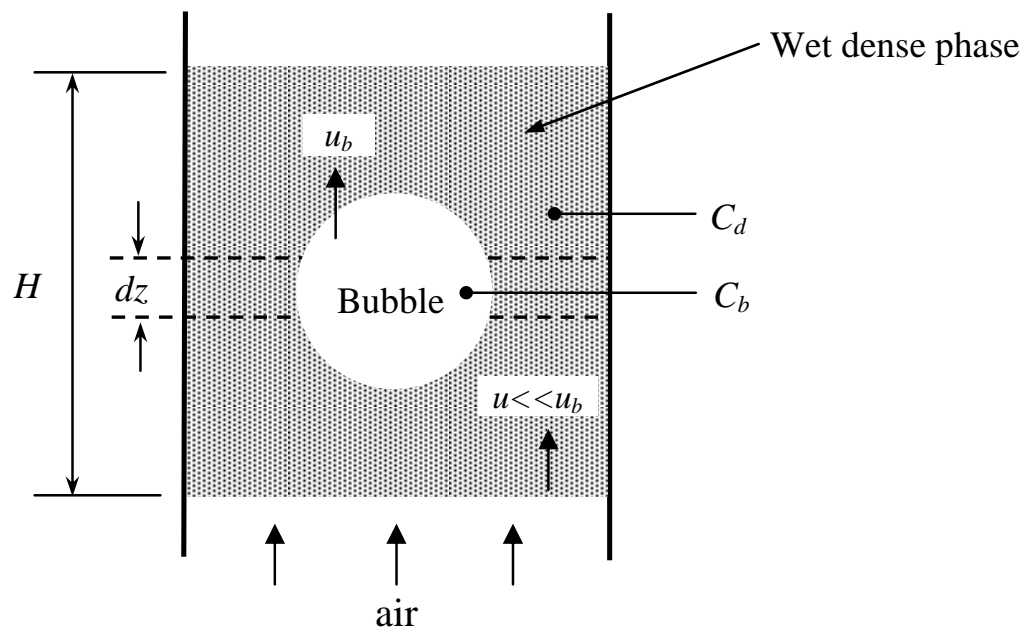

Figure 2 


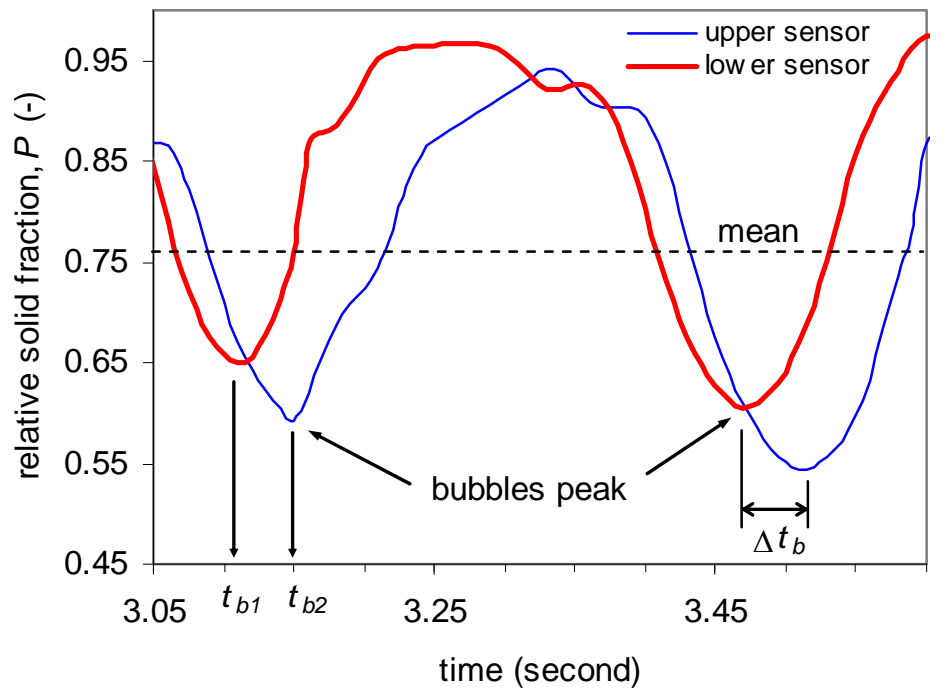

Figure 3 

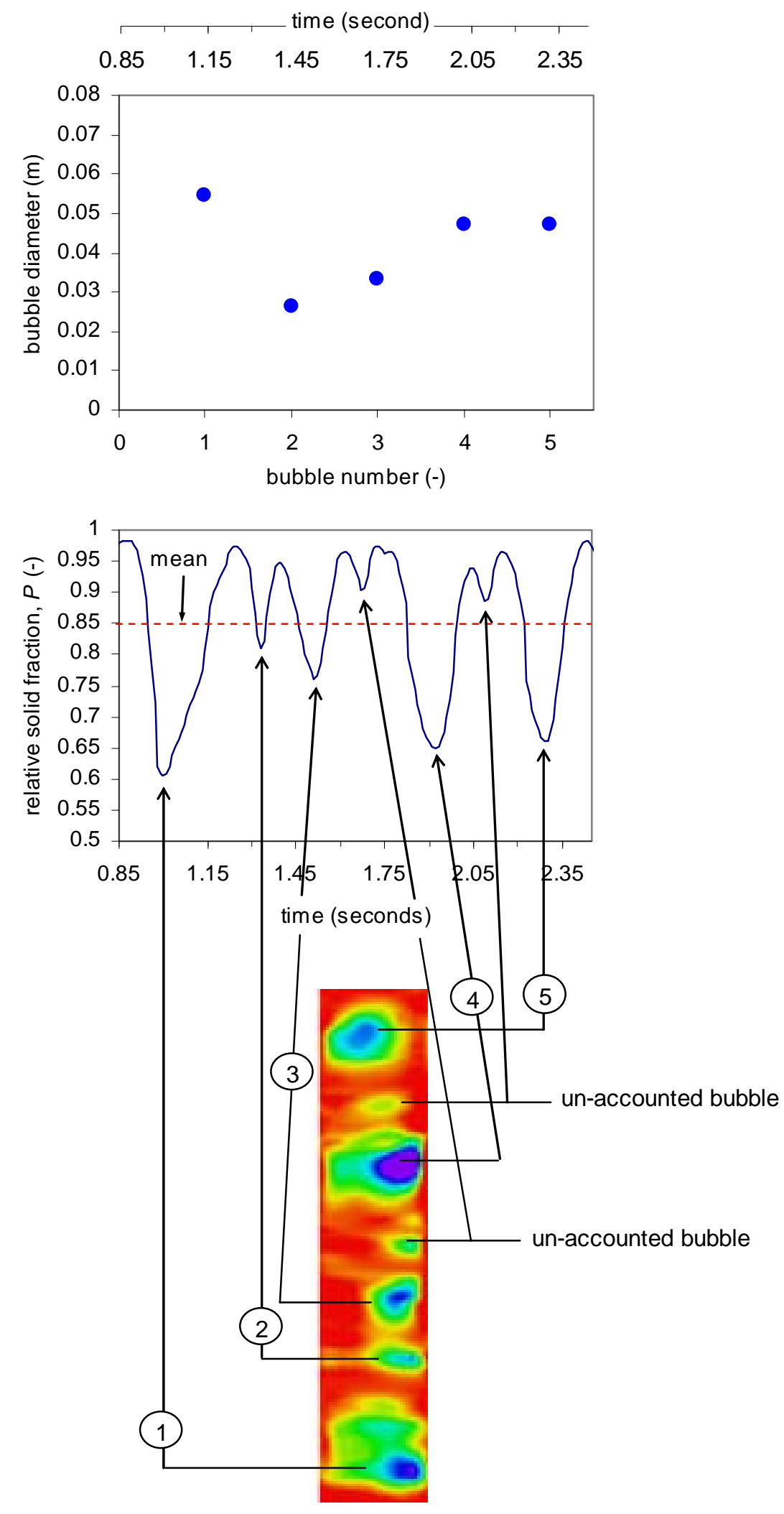

Figure 4 


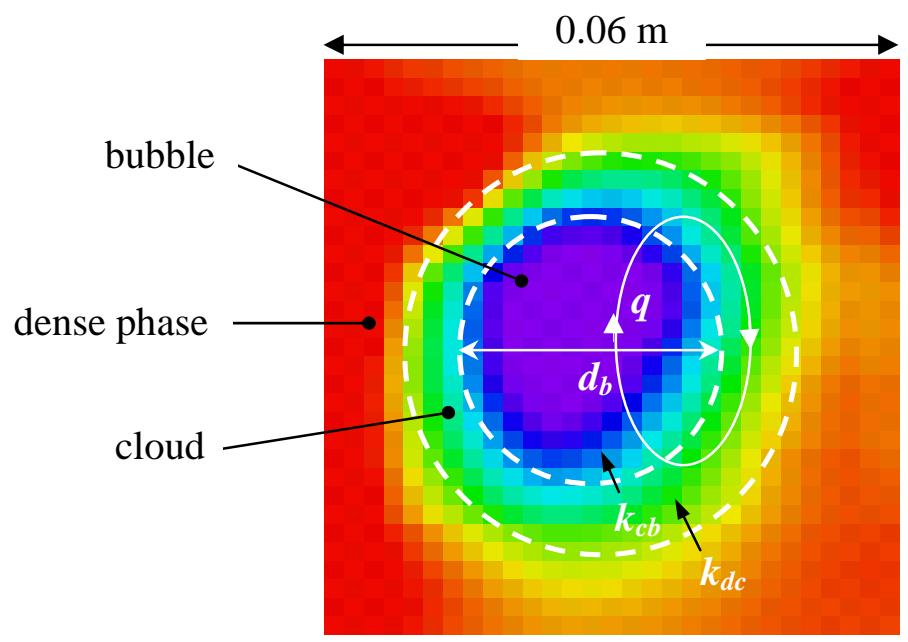

Figure 5 

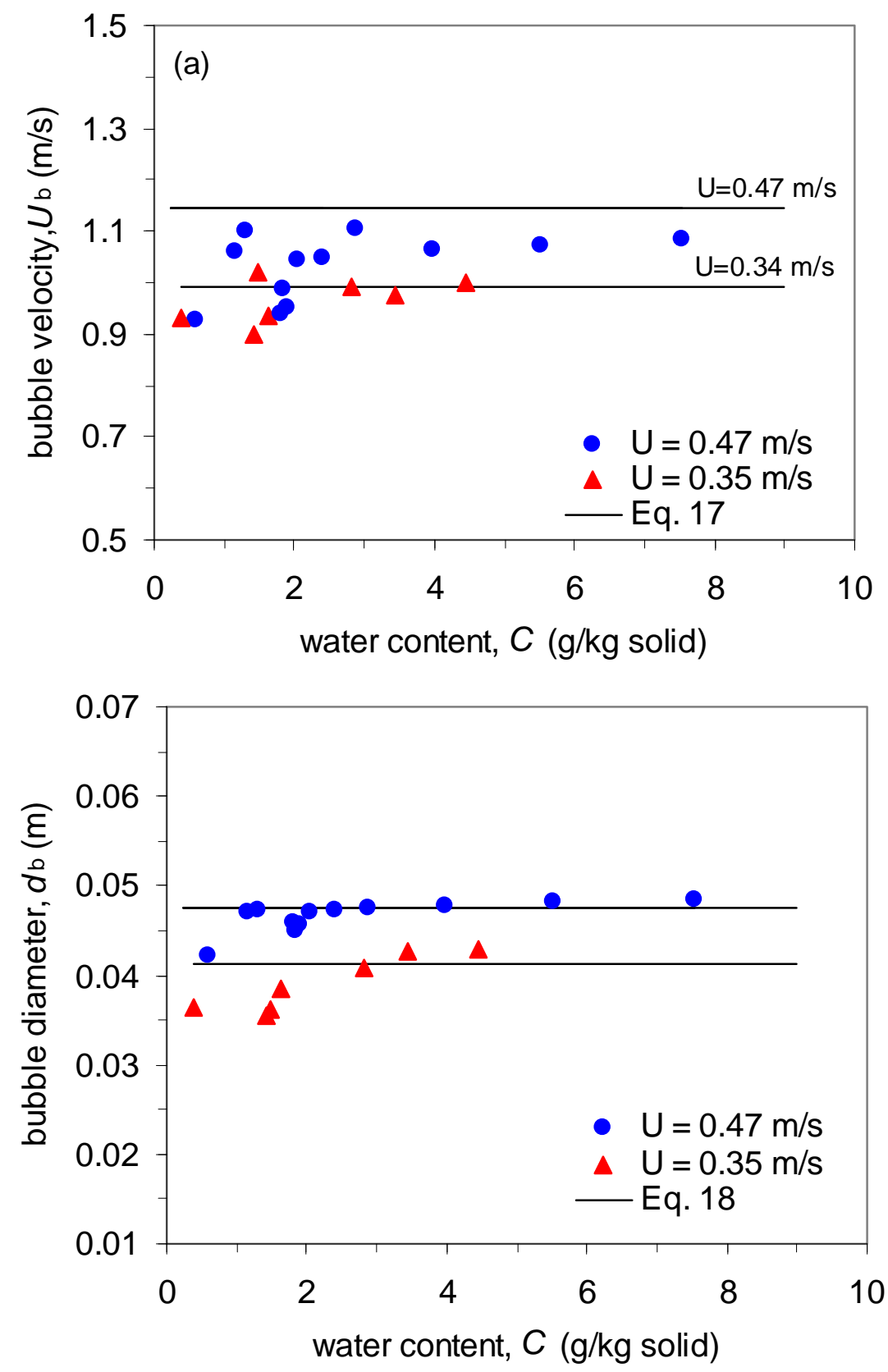

Figure 6 


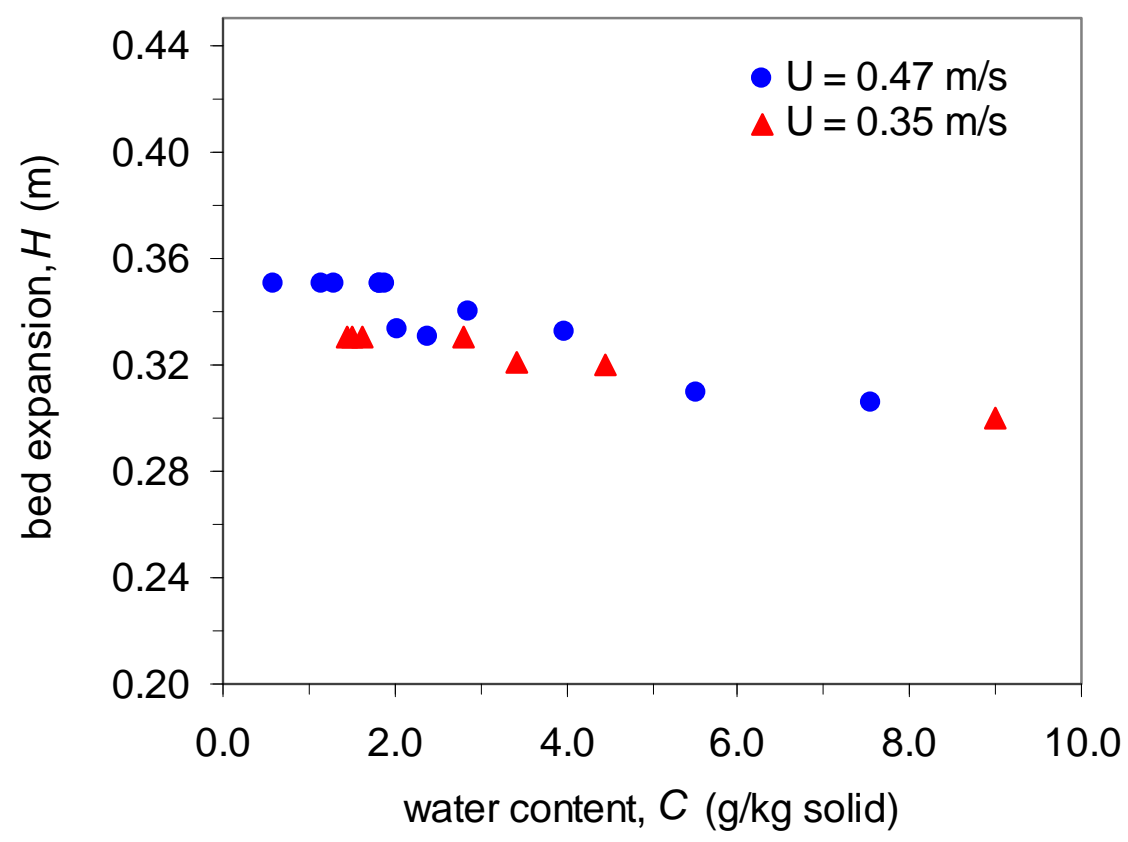

Figure 7 


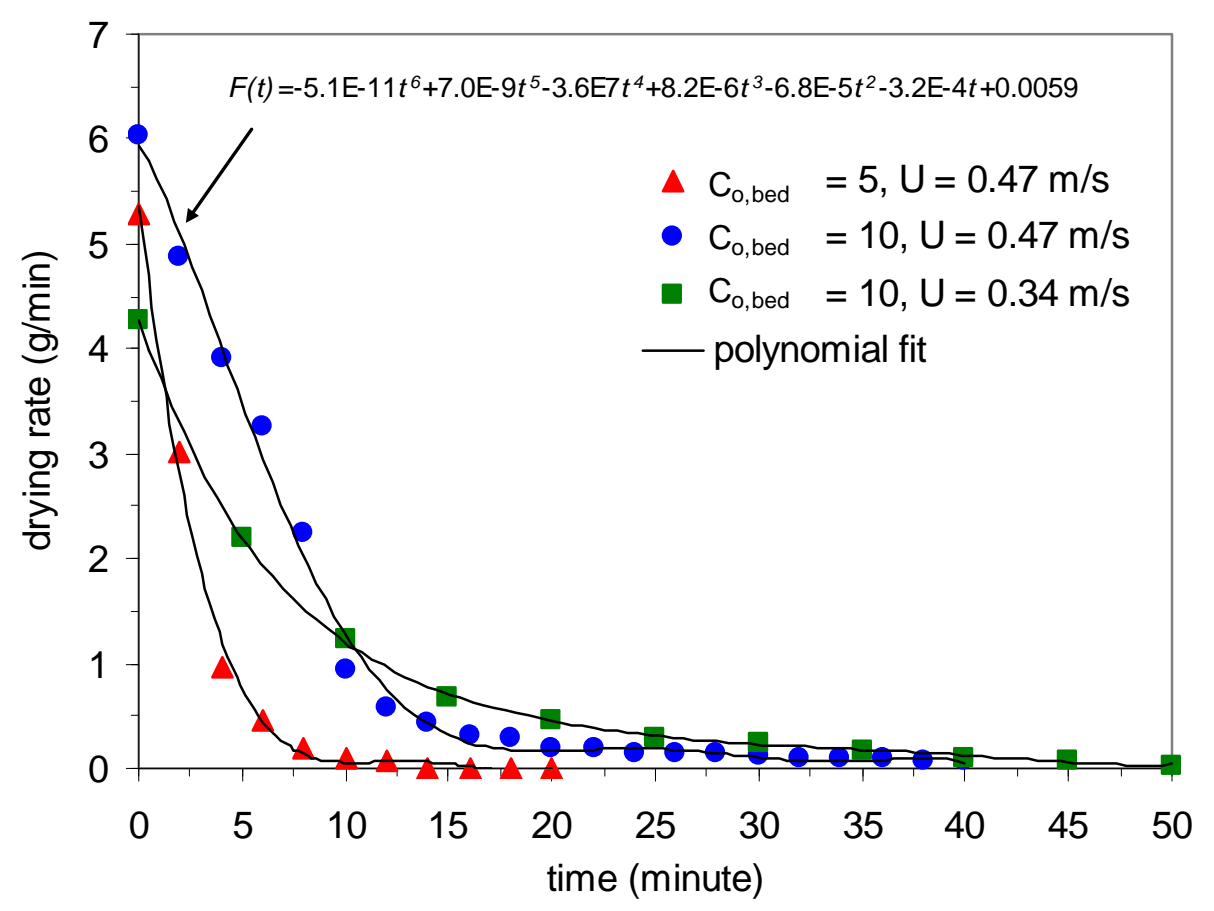

Figure 8 


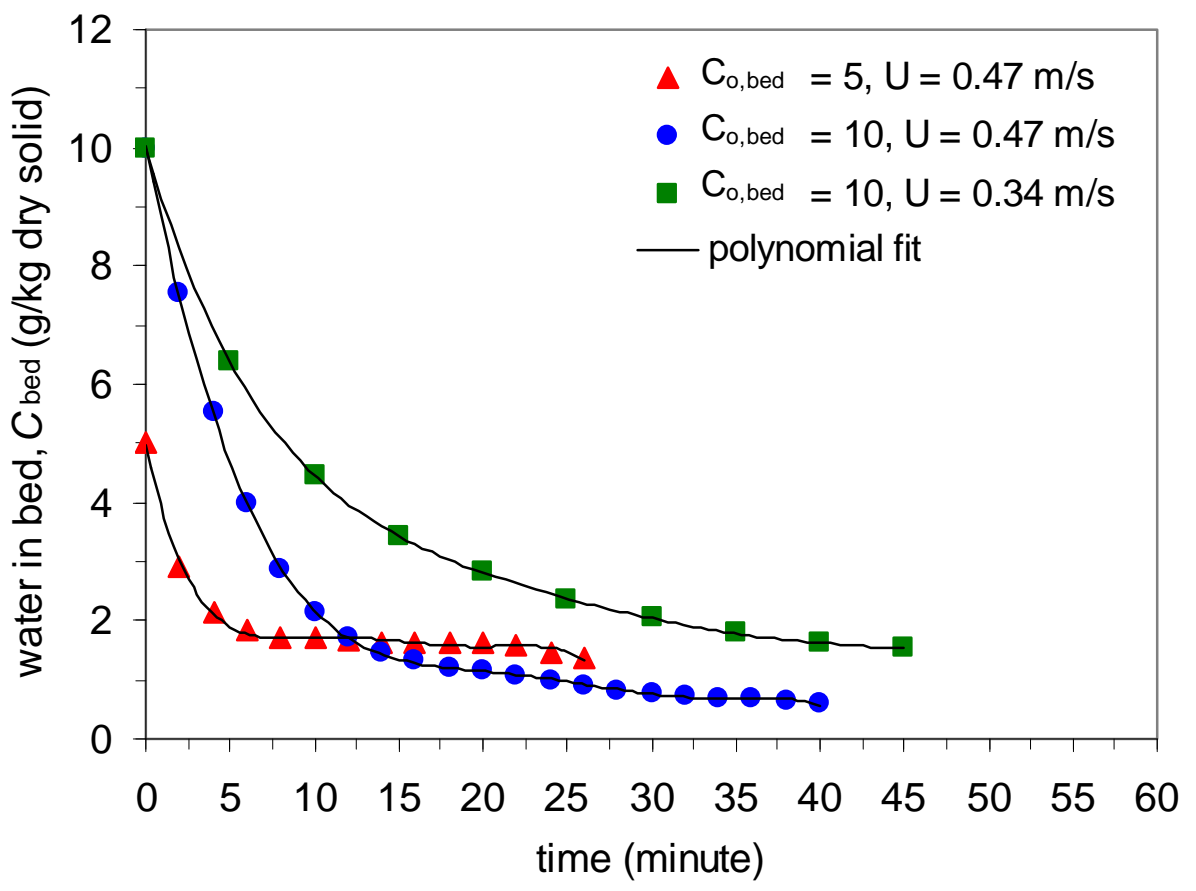

Figure 9 


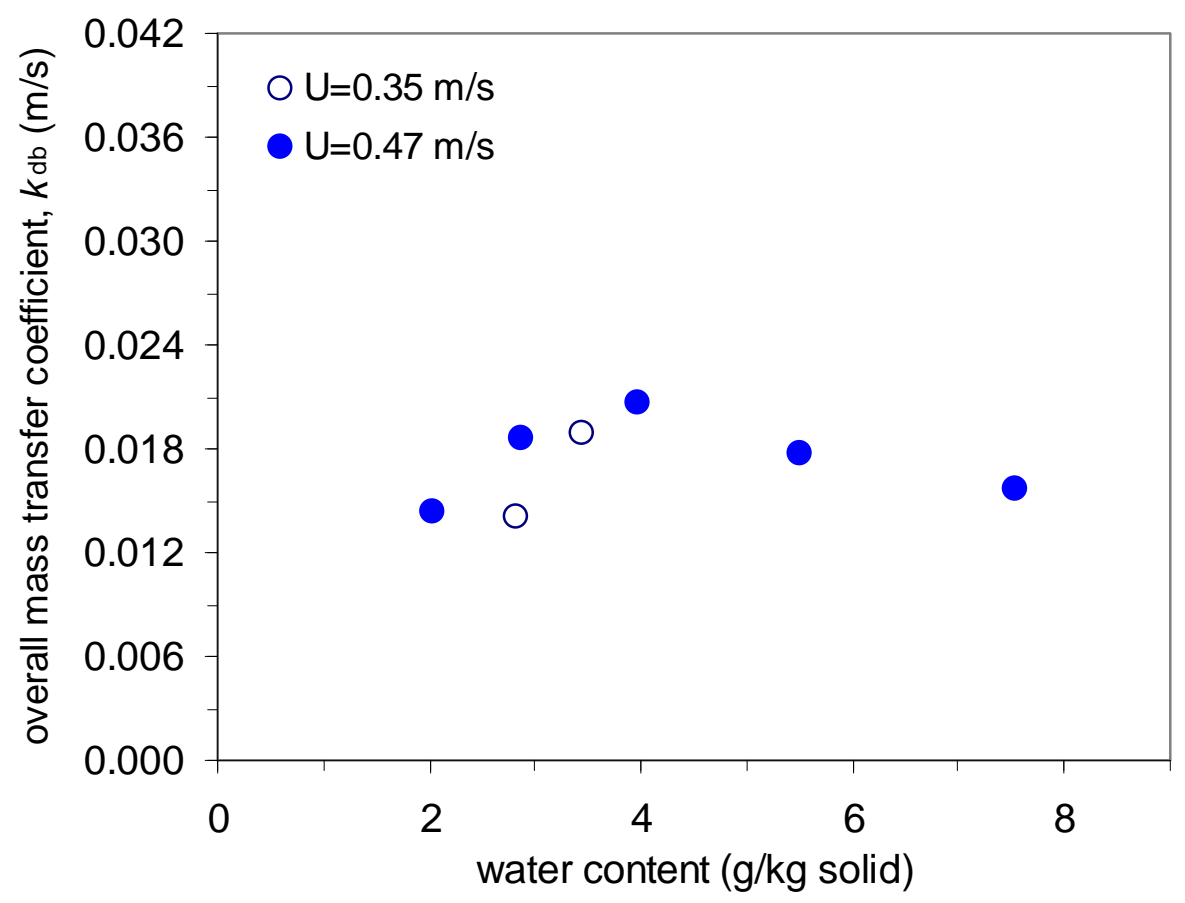

Figure 10 


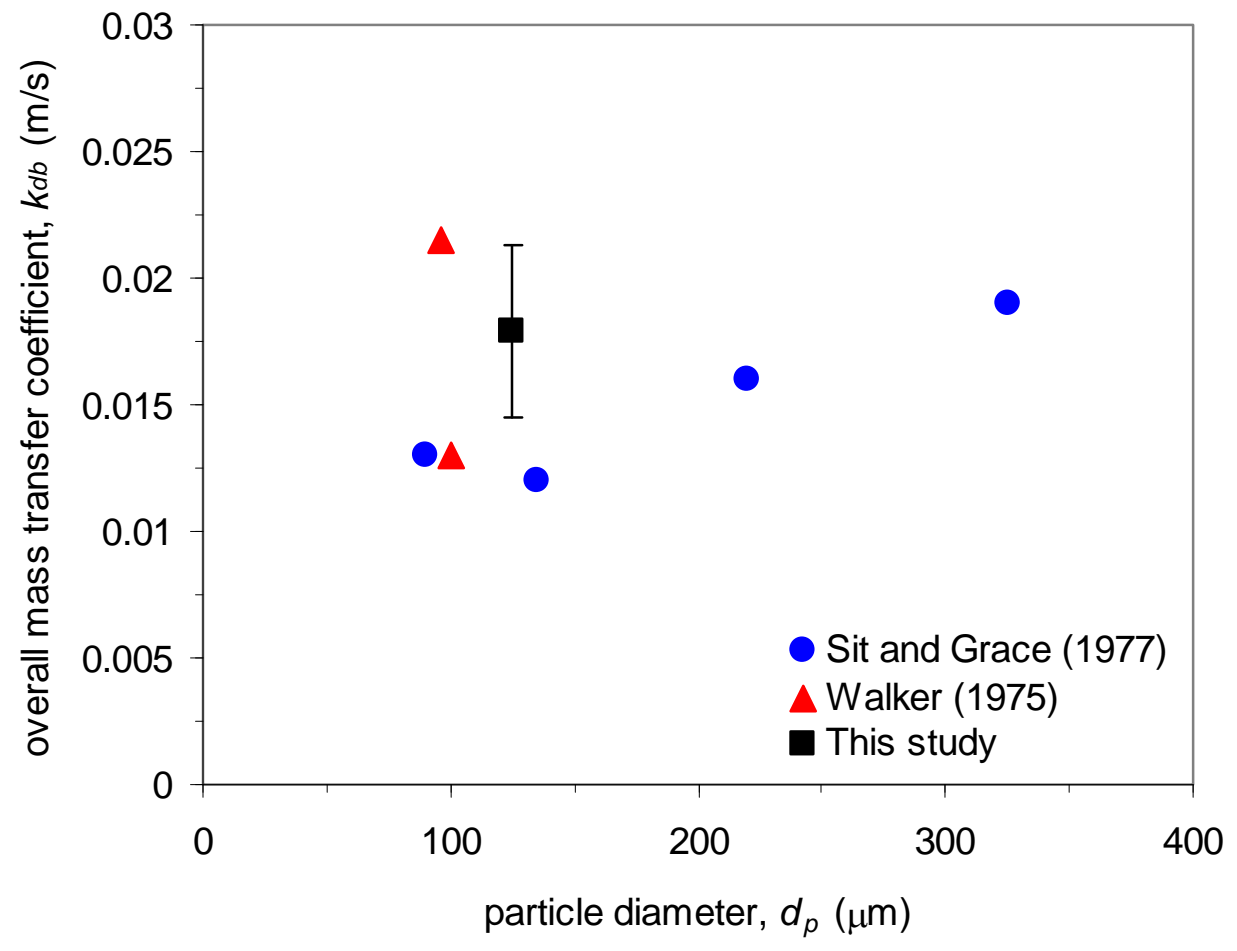

Figure 11 


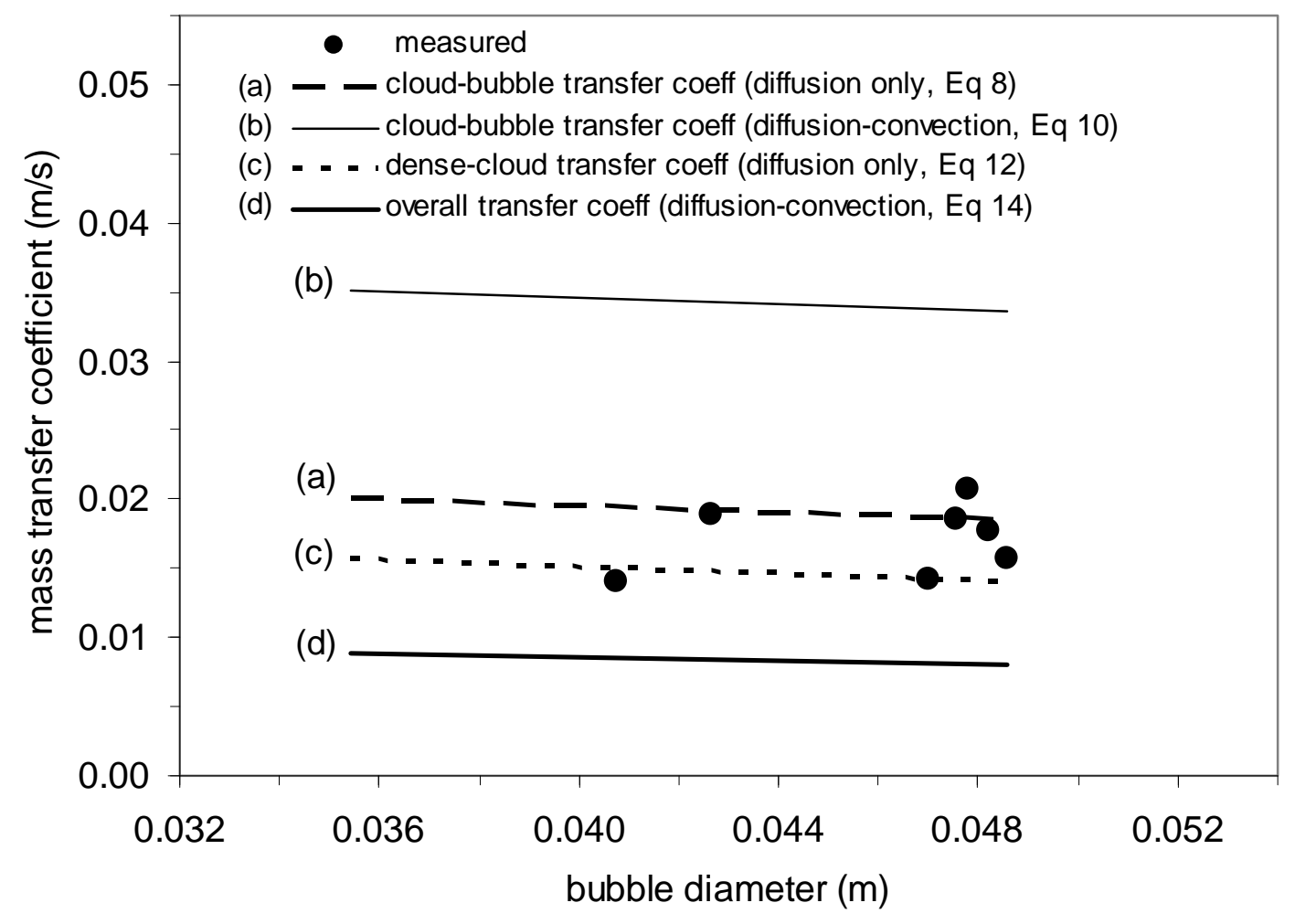

Figure 12 